\title{
Assessment of the ability of patients with scoliosis to actively correct the surface asymmetry of the trunk Agnieszka Bodnar-Nanus* ${ }^{*}$, Tomasz Kotwicki ${ }^{2}$, Marianna Białek ${ }^{3}$ and Andrzej M'hango ${ }^{3}$
} \author{
Sciences, Poznan, Poland and ${ }^{3}$ FITS Center Kielce, Poland \\ * Corresponding author \\ from $5^{\text {th }}$ International Conference on Conservative Management of Spinal Deformities \\ Athens, Greece. 3-5 April 2008 \\ Published: 15 January 2009 \\ Scoliosis 2009, 4(SuppI I):OI4 doi:I0.II86/I748-7|6I-4-SI-OI4
}

Address: ${ }^{1}$ Dept. of Public Health, College of Pedagogy and Administration, Poznan, Poland, ${ }^{2}$ Dept. of Pediatric Orthopedics, University of Medical

This abstract is available from: http://www.scoliosisjournal.com/content/4/SI/OI4

(c) 2009 Bodnar-Nanuśet al; licensee BioMed Central Ltd.

\section{Background}

Deformations of the torso in patients with progressive scoliosis can be precisely assessed with surface topography. Active auto-correction is one of essential exercises to be performed by patients with scoliosis.

\section{Purpose}

Evaluate what changes of surface parameters are introduced by active movements learned by patients with scoliosis from the physiotherapists.

\section{Methods}

Evaluation of the shape of the back in spontaneous position and after the active auto-correction. Fifty-eight girls, aged $14.0+/-1.8$ years, Cobb $31.3+/-11,0$ degrees, were educated to actively correct their posture, according to their type of scoliosis. There were 4 girls with single thoracic, 31 girls with double thoracic and lumbar and 23 girls with single thoracolumbar or lumbar scoliosis. Surface topography measures were done before and after a 12-days intensive in-patient rehabilitation program, focused on FITS physiotherapy.

\section{Results}

The POTSI index in actively corrected position after therapy was significantly lower $(\mathrm{p}<0.05)$ than POTSI in spontaneous position before therapy. The control measurement, which consisted of comparing POTSI in spontaneous and in corrected position before the patients started the therapy, revealed no significant change.

\section{Conclusion}

Patients with scoliosis are able to actively change the shape of their trunk. When non-educated, they cannot effectively decrease the trunk asymmetry. After intensive in-patient physiotherapy, they achieve the ability to actively reduce the surface deformity of their back.

\section{References}

I. Suzuki N, Inami T, Ono T, Kohno K, Asher MA: Analysis of Posterior Trunk Symmetry Index (POTSI) in Scoliosis. Stud Health Technol Inform 1999, 59:8I-84.

2. Bialek M, M'hango A: FITS concept: Functional Individual Therapy of Scoliosis. The Conservative Scoliosis Treatment:. Stud Health Technol Inform 2008, 135:250-261. 